\title{
Progesterone production in bovine luteal cells treated with drugs that modulate nitric oxide production
}

\author{
J. J. Jaroszewski ${ }^{1}$, M. Bogacki ${ }^{2}$ and D. J. Skarzynski ${ }^{3}$ \\ ${ }^{1}$ Department of Pharmacology, Faculty of Veterinary Medicine, University of Warmia and Mazury \\ in Olsztyn, Oczapowskiego 13, 10-719 Olsztyn, Poland; ${ }^{2}$ Pennington Biomedical Research Center, \\ Louisiana State University, Baton Rouge, LA 70808, USA; and ${ }^{3}$ Division of Reproductive Endocrinology \\ and Pathophysiology, Institute of Animal Reproduction and Food Research, PAS, Tuwima-St 10, \\ Olsztyn 10-747, Poland
}

The aim of this study was to investigate the influence of nitric oxide (NO) donors ( $S$-nitroso-L-acetyl penicillamine, spermine-NO complex and sodium nitroprusside) and NO synthase inhibitors $\left(N^{\omega}\right.$-nitro-L-arginine methyl ester, $N^{\omega}$ nitro-L-arginine, and ( \pm )-2-amino-5,6-dihydro-6-methyl$4 \mathrm{H}-1$,3-thiazine) on progesterone production by dispersed bovine luteal cells cultured for $24 \mathrm{~h}$. All NO donors inhibited progesterone production and increased nitrite or nitrate concentration in the medium in a dose-dependent manner. Secretion of progesterone was reduced to $75 \%$ $(P<0.01), 56 \% \quad(P<0.001)$ and $37 \%(P<0.001)$ by $S$-nitroso-L-acetyl penicillamine; to $65 \%(P<0.001), 45 \%$ $(P<0.001)$ and $33 \%(P<0.001)$ by spermine-NO complex and to $77 \%(P<0.05), 74 \%(P<0.01)$ and $54 \%$ $(P<0.001)$ by sodium nitroprusside treatments at concentrations of $10^{-5}, 10^{-4}$ and $10^{-3} \mathrm{moll}^{-1}$, respectively, compared with the concentration of this hormone meas- ured in cells cultured in medium alone. NO synthase inhibitors decreased significantly $(P<0.05)$ nitrite or nitrate concentration and increased progesterone secretion with different potency at different doses. Significant increases in progesterone production were observed after $N^{\omega}$-nitro-L-arginine methyl ester treatment at a concentration of $10^{-5} \mathrm{moll}^{-1}$ and $10^{-4} \mathrm{moll}^{-1}$, and after $N^{\omega}$-nitro-L-arginine administration at a concentration of $10^{-6} \mathrm{moll}^{-1}(P<0.01)$ and $10^{-5} \mathrm{moll}^{-1}(P<0.05)$, compared with the concentration of this hormone measured in control cells. The results indicate that both NO donors and NO synthase inhibitors regulate steroidogenesis in cultured bovine luteal cells from days 10 to 14 of the oestrous cycle; however, the degree of progesterone inhibition by NO donors and stimulation by NO synthase inhibitors was dependent on the drug used.

\section{Introduction}

During the last decade many studies have shown that nitric oxide $(\mathrm{NO})$, a highly reactive free radical, generated from L-arginine by nitric oxide synthase (NO synthase), acts as an important regulator of many physiological events (Moncada et al., 1991). The NO synthase occurs in two functional classes that can be distinguished by their dependence on calcium for activity (Moncada et al., 1991; Dong et al., 1996). The constitutive isoforms NO synthase, NO synthase I (neuronal NO synthase) and NO synthase III (endothelial NO synthase) bind calmodulin in a reversible and $\mathrm{Ca}^{2+}$-dependent manner and release $\mathrm{NO}$ for short periods in response to receptor stimulation (Moncada et al., 1991; Dong et al., 1996). The cytokineinducible isoform, NO synthase II (macrophage NO synthase) is calmodulin- and $\mathrm{Ca}^{2+}$-independent (Sessa, 1994; Dong et al., 1996).

Email: jerzyj@uwm.edu.pl
NO participates, with other substances, in the regulation of blood pressure (Ignarro, 1990), host defence (Bogdan, 2001; Eisenstein, 2001), neurotransmission (Kiss, 2000) and reproduction (Jaroszewski et al., 2001). In the ovary, $\mathrm{NO}$ is involved in the process of follicular development and ovulation (Jablonka-Shariff and Olson, 1998; Drazen et al., 1999), as well as corpus luteum function (Jaroszewski and Hansel, 2000; Skarzynski et al., 2000). Many NO donors and NO synthase inhibitors have been used to determine the role of $\mathrm{NO}$ in progesterone production. It has been shown that the NO donors, $S$-nitroso-L-acetyl penicillamine and $S$ nitrosoglutathione, cause a dose-dependent decrease in progesterone secretion by human granulosa-luteal cells (Van Voorhis et al., 1994). In contrast, NO synthase inhibitors, $N^{\omega}$-nitro-L-arginine methyl ester and $N^{G}$ methyl-L-arginine, did not affect progesterone release (Van Voorhis et al., 1994). Similarly, it has been shown that sodium nitroprusside, a NO donor, decreases progesterone secretion and aminoguanidine, but NO synthase inhibitor did not influence progesterone secretion in 
cultured cells obtained from luteinized rat ovaries (Olson et al., 1996). In contrast, another NO donor (diethylenetriamine/NO) demonstrated a dose-dependent increase in progesterone production in ovaries collected from immature, equine chorionic gonadotrophin (eCG)-treated rats (Dong et al., 1999). Recently, it has been shown that $S$-nitroso-L-acetyl penicillamine inhibited production of progesterone in dispersed bovine luteal cells (Skarzynski and Okuda, 2000). Perfusion of the bovine ovary with $N^{\omega}$-nitro-L-arginine methyl ester increased progesterone secretion at either mid- or late-luteal phases (Jaroszewski and Hansel, 2000). However, addition of $N^{\omega}$-nitro-Larginine methyl ester and $N^{\omega}{ }^{\omega}$-nitro-L-arginine (another NO synthase inhibitor) increased progesterone production by dispersed bovine luteal cells from mid- but not from early cycle corpus luteum (Skarzynski and Okuda, 2000).

These conflicting data from differently designed experiments, performed under various conditions, led us to perform an experiment in which the influence of three nitric oxide donors ( $S$-nitroso-L-acetyl penicillamine, spermine-NO complex and sodium nitroprusside) and three $\mathrm{NO}$ synthase inhibitors ( $N^{\omega}$-nitro-L-arginine methyl ester, $N^{\omega}$-nitro-L-arginine and $( \pm$ )-2-amino-5,6-dihydro6-methyl-4H-1,3-thiazine) on progesterone production by bovine luteal cells, cultured in the same system and under the same conditions, could be compared.

\section{Materials and Methods}

\section{Cell culture}

Ovaries with corpora lutea were collected from cows at a local abattoir within 10-15 min after slaughter, placed in ice-cold saline and transported to the laboratory. The stage of the oestrous cycle was determined by macroscopic observation of the ovaries and the uterus (Miyamoto et al., 2000) and corpora lutea were collected from ovaries and assigned to days 10-14 of the oestrous cycle. Enzymatic dissociation of the luteal tissue and the culture of luteal cells were performed as described by Skarzynski and Okuda (1999). Cell viability was greater than $85 \%$ as assessed by Trypan blue exclusion. The cell suspension contained about $20 \%$ large luteal cells, $70 \%$ small luteal cells and $10 \%$ endothelial cells or fibroblasts, but no erythrocytes.

The cells were adjusted to $1 \times 10^{5}$ viable cells $\mathrm{ml}^{-1}$ of cultured medium: Dulbecco's modified Eagle's medium (DMEM) and F-12 Ham's medium (DMEM-Ham's F$12 ; 1: 1(\mathrm{v} / \mathrm{v})$; Sigma, St Louis, MO) supplemented with $10 \%(\mathrm{v} / \mathrm{v})$ calf serum (Sigma) and $20 \mu \mathrm{g}$ gentamicin $\mathrm{ml}^{-1}$ (Gibco Laboratories, Grand Island, NY). The cells were cultured in 48-well culture plates (Costar, Cambridge, $\mathrm{MA})$ in a humidified incubator at $37.5^{\circ} \mathrm{C}$ in $5 \% \mathrm{CO}_{2}$ and $95 \%$ air atmosphere. After $24 \mathrm{~h}$, the cells were washed twice with serum-free DMEM and then medium was replaced by fresh DMEM-Ham's F-12 supplemented with $0.1 \% \quad(\mathrm{w} / \mathrm{v}) \quad$ BSA (Sigma), $0.5 \mathrm{mmol}$ ascorbic acid $\mathrm{I}^{-1}$ (Sigma), $5 \mathrm{ng}$ sodium selenite $\mathrm{ml}^{-1}$ (Sigma), $5 \mu \mathrm{g}$ holo-transferrin $\mathrm{ml}^{-1}$ (Sigma), and containing $20 \mu \mathrm{g}$ gentamicin $\mathrm{ml}^{-1}$. Simultaneously, the cells were treated for $24 \mathrm{~h}$ with various $\mathrm{NO}$ donors or inhibitors of $\mathrm{NO}$ production.

\section{Experiment 1}

The purpose of this experiment was to determine the effect of increasing doses of three NO donors on progesterone production and to evaluate the potency of each to cause NO liberation. In three separate replicates (two or three corpora lutea in each), the luteal cells were incubated with $S$-nitroso-L-acetyl penicillamine $\left(10^{-5}\right.$ to $10^{-3} \mathrm{moll}^{-1}$; Sigma), spermine-NO complex $\left(10^{-5}\right.$ to $10^{-3} \mathrm{moll}^{-1}$; Cayman Chemical Company, Ann Arbor, $\mathrm{MI})$, sodium nitroprusside $\left(10^{-5}\right.$ to $10^{-3} \mathrm{~mol} \mathrm{I}^{-1}$; Sigma) or with bovine LH (USDA-bLH-B-6; $100 \mathrm{ng} \mathrm{ml}^{-1}$ ) as a positive control.

\section{Experiment 2}

In this experiment, the effects of three NO synthase inhibitors $\left(10^{-6}\right.$ to $\left.10^{-4} \mathrm{~mol} \mathrm{I}^{-1}\right)$ on progesterone production and the potency of each to inhibition of NO releases were determined (three separate replicates, two or three corpora lutea each). The luteal cells were incubated with a non-selective NO synthase inhibitor $\left(N^{\omega}\right.$-nitro-Larginine methyl ester; Sigma), an irreversible inhibitor of NO synthase I and III and reversible inhibitor of NO synthase II ( $N^{\omega}{ }^{\omega}$-nitro-L-arginine; Sigma), a potent selective and reversible inhibitor of NO synthase II $(( \pm)$ 2-amino-5,6-dihydro-6-methyl-4H-1,3-thiazine; Sigma) or with LH (USDA-bLH-B-6; $100 \mathrm{ng} \mathrm{ml}^{-1}$ ) as a positive control.

After $24 \mathrm{~h}$ of incubation, culture media were collected and stored at $-20^{\circ} \mathrm{C}$ until assayed for progesterone and nitrite or nitrate.

\section{Progesterone and nitrite or nitrate determinations}

Progesterone in the culture media was assayed using a direct enzyme immunoassay as described by Okuda et al. (1997). The standard curve ranged from 0.39 to $100 \mathrm{ng} \mathrm{ml}^{-1}$ and the effective dose for $50 \%$ inhibition ( $\mathrm{ID}_{50}$ value) of the assay was $4.5 \mathrm{ng} \mathrm{m}^{-1}$. The intra- and interassay coefficients of variation were $6.9 \%$ and $10.1 \%$, respectively.

Nitrite or nitrate concentrations were determined using a colorimetric method (Griess Reagent; Green et al., 1982). Briefly, nitrite standard (Sigma) was diluted in medium (DMEM-Ham's F-12) to a final concentration of $100 \mu \mathrm{mol} \mathrm{I}^{-1}$ before determinations. Nitrate reductase $\left(0.2 \mathrm{U}(2 \mathrm{ml})^{-1}\right.$; Sigma) was dissolved in the dilution buffer $\left(10 \mathrm{mmol}_{\text {glycine }} \mathrm{I}^{-1}, 50 \mathrm{mmol} \mathrm{Mops} \mathrm{I}^{-1}\right.$ at $\mathrm{pH} 7.2,20 \%(\mathrm{v} / \mathrm{v})$ glycerol and $0.1 \%(\mathrm{w} / \mathrm{v}) \mathrm{BSA}$; Sigma) 
and NADPH (Sigma) was diluted in deionized water to a final concentration of $2 \mathrm{mmol}^{-1}$. All solutions were protected from light. The assay was performed in a standard flat-bottomed 96-well polystyrene microtitre plate (Corning Inc., Corning, NY). Standards $(100 \mu \mathrm{l}$ in serial dilution from $0-100 \mu \mathrm{mol} \mathrm{I}^{-1}$ ) or medium samples $(100 \mu \mathrm{l})$ in duplicate, $10 \mu \mathrm{l}$ of nitrate reductase solution (to convert nitrate to nitrite) and $10 \mu \mathrm{l}$ of $\mathrm{NADPH}$ solution were added to each well, and the plate was swirled for $20 \mathrm{~min}$ at room temperature. Thereafter, $100 \mu \mathrm{l}$ of Griess Reagent (Sigma; diluted in deionized water to the final concentration of $40 \mathrm{mg} \mathrm{ml}^{-1}$ directly before determination) was added to each well, mixed gently, protected from light and allowed to incubate for $15 \mathrm{~min}$ at room temperature. The absorbance was measured within $30 \mathrm{~min}$ using a $540 \mathrm{~nm}$ filter and plate reader (Bio-Rad, Hercules, CA). Concentrations of nitrite were determined using a standard curve constructed by plotting absorbance values versus nitrite standard concentrations. Sensitivity of the method was $0.085 \mu \mathrm{g} \mathrm{ml}^{-1}$ and the standard curve ranged from $0.05 \mu \mathrm{g} \mathrm{ml}^{-1}$ to $6.9 \mu \mathrm{g} \mathrm{ml}^{-1}$.

The intra- and interassay coefficients of variation were on average $8.2 \%$ and $14.9 \%$, respectively.

\section{Statistical analysis}

Experimental data are presented as mean \pm SEM of three separate experiments each performed in triplicate. The influence of $\mathrm{NO}$ donors on progesterone secretion and nitrite or nitrate concentration was described by a linear regression using a computer program GraphPad PRISM (GraphPad Software, San Diego, CA). The statistical significance of differences between controls and treated groups was calculated by one-way ANOVA followed by Bonferroni's multiple comparison test (GraphPad PRISM). A value of $P<0.05$ was considered to be significant.

\section{Results}

Nitrite or nitrate concentrations in the medium after luteal cell treatment with NO donors or NO synthase inhibitors

Increasing doses of all NO donors resulted in a dosedependent increase of nitrite or nitrate concentrations, as shown by the linear regression $(r=0.987, P<0.001$; $r=0.838, P<0.001$ and $r=0.779, P<0.001$ for $S$-nitroso-L-acetyl penicillamine, spermine-NO complex and sodium nitroprusside, respectively). Significant increases in NO production were observed after treatment with $S$-nitroso-L-acetyl penicillamine at a concentration of $10^{-3} \mathrm{moll}^{-1}(P<0.001)$ and after administration of spermine-NO complex at $10^{-4} \mathrm{~mol} \mathrm{I}^{-1}$ and $10^{-3} \mathrm{moll}^{-1}(P<0.001)$ compared with controls

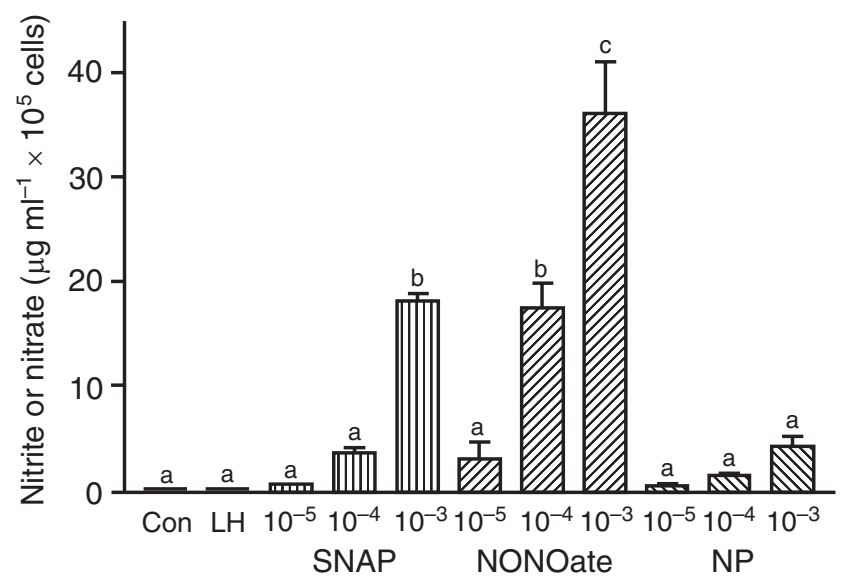

Fig. 1. Nitrite or nitrate concentrations in the medium after incubation of bovine luteal cells for $24 \mathrm{~h}$ in medium alone (control) or with $\mathrm{LH}$ and increasing concentrations of nitric oxide donors: S-nitroso-L-acetyl penicillamine (SNAP, 四), sperminenitric oxide complex (NONOate, 国) and sodium nitroprusside $(N P, \mathbb{N})$. Data are expressed as the means \pm SEM of three separate experiments, each performed in triplicate. ${ }^{\mathrm{a}-\mathrm{c}}$ Different subscripts indicate significant differences $(P<0.05)$, as determined by oneway ANOVA followed by Bonferroni's multiple comparison test. Con: control.

(Fig. 1). Moreover, the concentration of nitrite or nitrate in the medium after treatment of cells with spermine-NO complex at $10^{-4} \mathrm{moll}^{-1}$ was significantly higher $(P$ $<0.001$ ) than after $S$-nitroso-L-acetyl penicillamine and sodium nitroprusside administration at the same concentrations. At the highest dose, spermine-NO complex released significantly more $\mathrm{NO}$ than did $S$-nitroso-L-acetyl penicillamine and sodium nitroprusside $(P<0.001)$ and $S$-nitroso-L-acetyl penicillamine released significantly more $\mathrm{NO}$ than did sodium nitroprusside $(P<0.001$; Fig. 1$)$. LH did not affect nitrite or nitrate concentration compared with controls (Fig. 1).

The changes in nitrite or nitrite concentrations in the medium collected after treatment of luteal cells with $\mathrm{NO}$ synthase inhibitors were less marked than after treatment with $\mathrm{NO}$ donors (Fig. 2).

Treatment with $N^{\omega}$-nitro-L-arginine methyl ester decreased nitrite or nitrate concentration to $62 \%(P<$ $0.001), 54 \%(P<0.001)$ and $64 \%(P<0.001)$ of the control concentration at $10^{-6} \mathrm{~mol} \mathrm{I}^{-1}, 10^{-5} \mathrm{~mol} \mathrm{I}^{-1}$ and $10^{-4} \mathrm{~mol} \mathrm{I}^{-1}$, respectively (Fig. 2). Increasing doses of $N^{\omega}$-nitro-L-arginine decreased nitrite or nitrate concentrations to $73 \%(P<0.05), 65 \%(P<0.001)$ and $69 \%$ $(P<0.01)$, and $( \pm)$-2-amino-5,6-dihydro-6-methyl-4H1,3-thiazine reduced nitrite or nitrate concentrations to 79\% $(P>0.05), 62 \%(P<0.001)$ and $69 \%(P<0.01)$ compared with the concentration measured in cells cultured in medium alone (Fig. 2). 


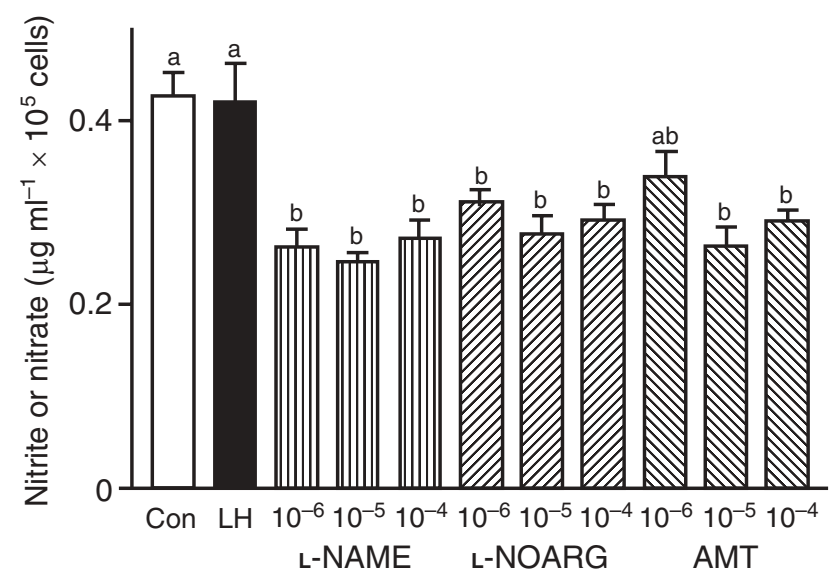

Fig. 2. Nitrite or nitrate concentrations in the medium after incubation of bovine luteal cells for $24 \mathrm{~h}$ in medium alone (control) or with $\mathrm{LH}$ and increasing concentrations of nitric oxide synthase inhibitors: $N^{\omega}$-nitro-L-arginine methyl ester (L-NAME, 皿), $N^{\omega}$-nitro-

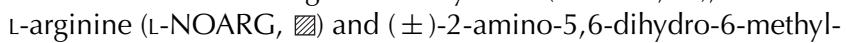
$4 \mathrm{H}-1,3$-thiazine $(\mathrm{AMT}, \mathbb{\mathbb { N }}$ ). Data are expressed as the means \pm SEM of three separate experiments, each performed in triplicate. ${ }^{a, b}$ Different subscripts indicate significant differences $(P<0.05)$, as determined by one-way ANOVA followed by Bonferroni's multiple comparison test. Con: control.

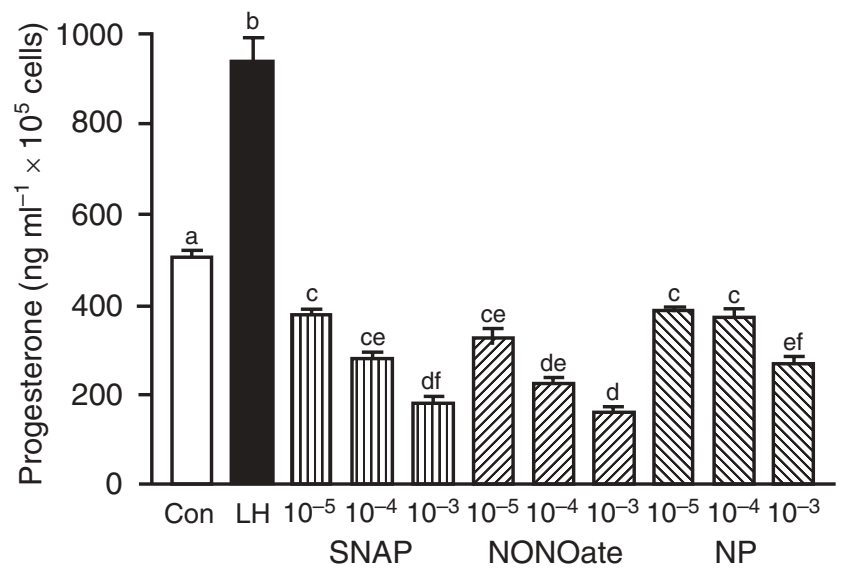

Fig. 3. Secretion of progesterone by cultured bovine mid-luteal cells after incubation for $24 \mathrm{~h}$ in medium alone (control) or with $\mathrm{LH}$ and increasing concentrations of nitric oxide donors: $S$-nitroso-L-acetyl penicillamine (SNAP, 皿), spermine-nitric oxide complex (NONOate, 四) and sodium nitroprusside (NP, $\mathbb{Q})$. Data are expressed as the means \pm SEM of three separate experiments, each performed in triplicate. ${ }^{\mathrm{a}-\mathrm{f}}$ Different subscripts indicate significant differences $(P<0.05)$, as determined by one-way ANOVA followed by Bonferroni's multiple comparison test. Con: control.

\section{Secretion of progesterone by luteal cells incubated with} NO donors

LH significantly increased $(P<0.001)$ progesterone secretion from cultured luteal cells after $24 \mathrm{~h}$ of incubation, indicating that cultured cells were react-

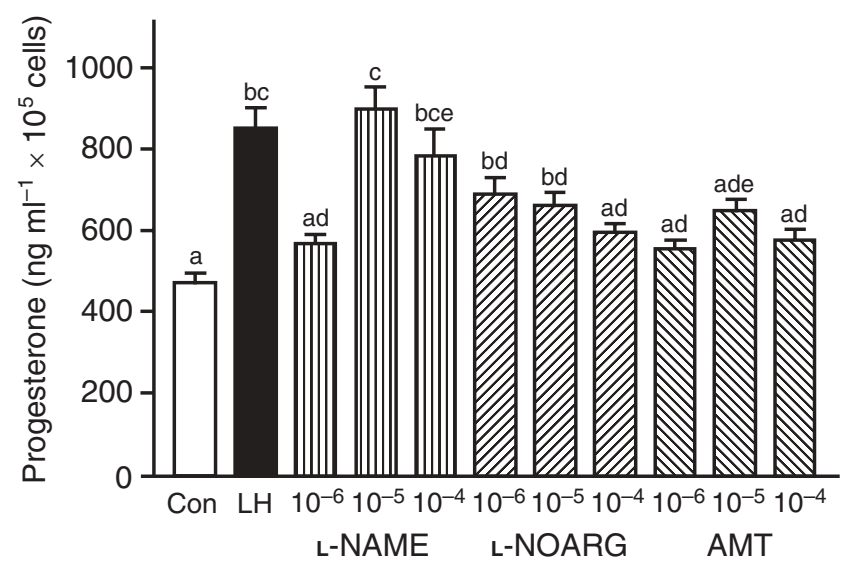

Fig. 4. Progesterone secretion from bovine mid-luteal cells cultured for $24 \mathrm{~h}$ in medium alone (control) or with $\mathrm{LH}$ and increasing concentrations of nitric oxide synthase inhibitors: $N^{\omega}$-nitro-L-arginine methyl ester (L-NAME, 四), $N^{\omega}$-nitro-L-arginine (L-NOARG, 四) and ( \pm )-2-amino-5,6-dihydro-6-methyl-4H-1,3thiazine $(A M T, \mathbb{N})$. Data are expressed as the means \pm SEM of three separate experiments, each performed in triplicate. ${ }^{a-e}$ Different subscripts indicate significant differences $(P<0.05)$, as determined by one-way ANOVA followed by Bonferroni's multiple comparison test. Con: control.

ive during the entire experimental period (Fig. 3). All nitric oxide donors inhibited progesterone production in a dose-dependent manner, as shown by the linear regression $(r=0.723, P<0.001 ; r=0.599$, $P<0.001 ; \quad r=0.624, P<0.001$ for $S$-nitroso-L-acetyl penicillamine, spermine-NO complex and sodium nitroprusside, respectively). $S$-Nitroso-L-acetyl penicillamine inhibited progesterone production to $75 \%(P<0.01)$, $56 \%(P<0.001)$ and $37 \%(P<0.001)$ of the control concentration after treatment with $10^{-5} \mathrm{moll}^{-1}$, $10^{-4} \mathrm{moll}^{-1}$ and $10^{-3} \mathrm{moll}^{-1}$, respectively (Fig. 3). Increasing doses of spermine-NO complex caused a decrease in progesterone concentrations to $65 \%$ $(P<0.001), \quad 45 \% \quad(P<0.001)$ and $33 \% \quad(P<0.001)$ of the concentration measured in cells cultured in medium alone (Fig. 3). The smallest reduction of progesterone production was observed after sodium nitroprusside treatment by $77 \%\left(10^{-5} \mathrm{~mol} \mathrm{I}^{-1}, P<0.05\right)$, $74 \%\left(10^{-4} \mathrm{moll}^{-1}, P<0.01\right)$ and $54 \%\left(10^{-3} \mathrm{moll}^{-1}\right.$, $P<0.001)$ of the control concentration, respectively (Fig. 3). Spermine-NO complex at $10^{-4} \mathrm{moll}^{-1}$ and $10^{-3} \mathrm{moll}^{-1}$ reduced significantly more progesterone production compared with the same concentrations of sodium nitroprusside $(P<0.05 ;$ Fig. 3$)$.

Secretion of progesterone by luteal cells incubated with NO synthase inhibitors

NO synthase inhibitors increased progesterone secretion, with different potencies at different doses (Fig. 4). $N^{\omega}$-Nitro-L-arginine methyl ester increased progesterone secretion to $121 \%(P>0.05), 190 \%(P<0.001)$ and 
$167 \%(P<0.001)$ at $10^{-6} \mathrm{moll}^{-1}, 10^{-5} \mathrm{moll}^{-1}$ and $10^{-4} \mathrm{molI}^{-1}$, respectively, compared with the control. Increasing doses of $N^{\omega}$-nitro-L-arginine increased progesterone secretion to $146 \%(P<0.01), 141 \%(P<$ $0.05)$ and $126 \%(P>0.05)$ and $( \pm)$-2-amino-5,6dihydro-6-methyl-4H-1,3-thiazine to $119 \%(P>0.05)$, $138 \%(P=0.053)$ and $123 \%(P>0.05)$ compared with the control group. A higher stimulation of progesterone production was observed after $N^{\omega}$-nitro-L-arginine methyl ester administration at $10^{-5} \mathrm{moll}^{-1}(P<0.001)$ and $10^{-4} \mathrm{moll}^{-1}(P<0.01)$ compared with the dose of $10^{-6} \mathrm{~mol} \mathrm{I}^{-1}$. Moreover, $N^{\omega}$-nitro-L-arginine methyl ester at $10^{-5} \mathrm{~mol} \mathrm{I}^{-1}$ stimulated secretion of this hormone with a higher potency than the same dose of $N^{\omega}$-nitroL-arginine $(P<0.01)$ and $( \pm)$-2-amino-5,6-dihydro6-methyl-4H-1,3-thiazine $(P<0.001)$. Similarly, $N^{\omega_{-}}$ nitro-L-arginine methyl ester at $10^{-4}$ mol I-1 caused a significantly higher increase in progesterone secretion than the same doses of $N^{\omega}$-nitro-L-arginine and $( \pm)-2$ amino-5, 6-dihydro-6-methyl-4H-1,3-thiazine $(P<0.05$; Fig. 4).

\section{Discussion}

The results of the present study demonstrate that all three NO donors inhibited progesterone secretion in a dose-dependent manner. Differences in the degree of inhibition of progesterone production by the $\mathrm{NO}$ donors were probably due to differences in the release of $\mathrm{NO}$ during cell culture, as reflected by nitrite or nitrate concentrations in the medium. Sodium nitroprusside, which releases $\mathrm{NO}$ at a lower concentration than $S$-nitroso-Lacetyl penicillamine and spermine-NO complex, was the least potent in inhibiting progesterone secretion. However, spermine-NO complex and $S$-nitroso-L-acetyl penicillamine were equally efficient in inhibiting progesterone secretion, even though spermine-NO complex was much more effective in releasing $\mathrm{NO}$.

The inhibition of progesterone secretion by $S$-nitrosoL-acetyl penicillamine observed in the present study is in agreement with previous data of Skarzynski and Okuda (2000), which indicated a dose-dependent decrease of progesterone production in cultured bovine luteal cells. $S$-Nitroso-L-acetyl penicillamine also inhibits progesterone production in human granulosa-luteal cells (Van Voorhis et al., 1994) and decreases gonadotrophinstimulated progesterone production in ovaries from NOdeficient rats (Dunnam et al., 1999). A similar inhibitory influence on progesterone secretion was observed after sodium nitroprusside addition to cells obtained from luteinized rat ovaries, incubated for $72 \mathrm{~h}$ (Olson et al., 1996) and to rabbit corpora lutea collected at 4 and 9 days of pseudopregnancy (Gobbetti et al., 1999). However, the inhibitory effect was greater in corpora lutea from day 9 than in those from day 4 of pseudopregnancy. The greatest decrease in progesterone production in our study was observed after treatment with spermine-NO complex. Friden et al. (2000) showed that spermineNO complex decreased progesterone secretion in human hCG-stimulated dispersed luteal cells; however, this effect was observed in cells from the late-, but not the mid-luteal phase.

As expected, the NO synthase inhibitors $\left(N^{\omega}\right.$-nitro-Larginine methyl ester and $N^{\omega}$-nitro-L-arginine) stimulated progesterone production by cultured bovine lutal cells. However, the increase produced by $( \pm)$-2-amino-5,6dihydro-6-methyl-4H-1,3-thiazine was not statistically significant. Skarzynski and Okuda (2000) observed a similar stimulatory influence of $N^{\omega}$-nitro-L-arginine methyl ester and $N^{\omega}$-nitro-L-arginine on progesterone secretion. The strongest immunostaining for $\mathrm{NO}$ synthase III was observed in mid- and the late-luteal phase, and the highest immunostaining of NO synthase II was seen just before luteolysis (Skarzynski et al., 2001). Because ( \pm )-2-amino-5,6-dihydro-6-methyl-4H-1,3-thiazine is a potent selective $\mathrm{NO}$ synthase II inhibitor and the studies were conducted on corpora lutea from day 10 to day 14 of the ovarian cycle during which $\mathrm{NO}$ synthase III is localized in high quantity, lower stimulation of progesterone production after $( \pm$ )-2-amino-5,6-dihydro-6-methyl-4H1,3-thiazine stimulation compared with non-selective $N^{\omega}$-nitro-L-arginine methyl ester may be a consequence of lower activity of NO synthase II in the mid-luteal cells compared with the late-luteal cells. The phase dependence of $\mathrm{NO}$ influence on progesterone production has been described in cattle (Skarzynski and Okuda, 2000), humans (Friden et al., 2000), rats (Motta et al., 2001) and rabbits (Gobbetti et al., 1999). Moreover, results of many studies indicate that the mechanism controlling luteal regression in cattle is an immune cell- and immune response-dependent process (Pate and Landis Keyes, 2001; Petroff et al., 2001; Taniguchi et al., 2002). The expression of NO synthase II is correlated with cytotoxic or cytostatic events and results in a sustained synthesis of NO, which in turn induces apoptotic cell death (Rosselli et al., 1998). These findings confirmed our suggestion that less evident changes in progesterone production observed after ( \pm )-2-amino-5,6-dihydro-6methyl-4H-1,3-thiazine treatment may be a result of less $\mathrm{NO}$ synthase II activity in the bovine mid-luteal cells.

In the present study, treatment with NO synthase inhibitors decreased $\mathrm{NO}$ production and increased secretion of progesterone. These findings differ in part from the results of Olson et al. (1996), which indicated that treatment with $N^{\omega}$-nitro-L-arginine methyl ester reduced production of endogenous $\mathrm{NO}$ in a dose-dependent manner but did not affect progesterone production by cells obtained from luteinized rat ovaries. However, the stimulatory influence of $\mathrm{NO}$ synthase inhibitors on progesterone secretion observed in the present study is in agreement with the results obtained after addition of $N^{\omega}$-nitro-L-arginine methyl ester or $N^{G}$-methyl-L-arginine to incubated corpora lutea of pseudopregnant rats (Motta and Gimeno, 1997) and rabbits (Gobbetti et al., 1999). 
Other studies indicate that NO plays a role not only as a modulator of steroidogenesis but also as survival or cell death induction factor in the ovary (Basini et al., 1998). The dual effects of NO seem to be dose-dependent (Basini et al., 1998) and cell typespecific (Burney et al., 1997). High concentration of NO inhibits DNA fragmentation in the bovine granulosa cells and in low concentration stimulates cellular apoptosis in granulosa cells only from large follicles (Basini et al., 1998). Recently it was shown that spermineNO complex strongly reduced viability of the bovine luteal cells, whereas $N^{\omega}$-nitro-L-arginine methyl ester indicates its opposite effect (A. Korzekwa, K. Okuda, J. J. Jaroszewski and D. J. Skarzynski, unpublished). Therefore, inhibition of progesterone production after treatment with $\mathrm{NO}$ donors, observed in the present study, may be a consequence of inhibition of steroidogenesis and reduction of the viability of luteal cells.

$\mathrm{NO}$ is known to inhibit progesterone production directly via inhibition of enzymes involved in steroidogenesis (Wink et al., 1993) or indirectly via activation of some luteolytic factors, that is endothelin 1 (Levy et al., 2000; Hinckley and Milvae, 2001) or leukotriene $C_{4}$ (Bogacki et al. 2002). Therefore, blocking NO production by NO synthase inhibitors associated with increase of progesterone secretion, observed in bovine corpora lutea, may also be a result of abolition of the NO inhibitory direct effect on steroidogenic enzymes or indirect luteolytic factors output. The NO-NO synthase systemrelated luteotrophic or luteolytic effects triggered in rabbit corpora lutea by exogenous $\mathrm{PGE}_{2}$ or $\mathrm{PGF}_{2 \alpha}$ in vitro were observed by Boiti et al. (2000). During simultaneous administration of $N^{\omega}$-nitro-L-arginine methyl ester and dinoprost (an analogue of $\mathrm{PGF}_{2 \alpha}$ ) into the bovine corpora lutea in vivo, $\mathrm{N}^{\omega}$-nitro-L-arginine methyl ester inhibited secretion of luteolytic $\mathrm{PGF}_{2 \alpha}$ but not luteotrophic $\mathrm{PGE}_{2}$ (Bogacki et al., 2002). This finding confirmed that the stimulation of progesterone production by $\mathrm{NO}$ synthase inhibitor may be in part mediated indirectly by the changes in arachidonic acid pathway. Therefore, NO appears to play an important role in the regulation of corpus luteum function as one of many components of an autocrine or paracrine cascade; however, a complete explanation of its role still needs further study.

In conclusion, the results of the present study demonstrate that nitric oxide donors inhibit and nitric oxide inhibitors increase progesterone production, by cultured bovine luteal cells at days 10-14 of the oestrous cycle. The degree of progesterone inhibition after NO donor treatment and stimulation after NO synthase inhibitors is dependent on the donor or inhibitor used. The results of the present study resolve some of the previous conflicting reports, since they compare the donors and inhibitors under identical conditions.

The authors thank S. Okrasa of the University of Warmia and Mazury in Olsztyn, Poland for antiserum of progesterone.
The critical reading of the manuscript by $W$. Hansel is greatly appreciated. This research was supported by Grants of the State Committee for Scientific Research (KBN 5P06K012 19).

\section{References}

Basini G, Baratta M, Ponderato N, Bussolati S and Tamanini C (1998) Is nitric oxide an autocrine modulator of bovine granulosa cell function? Reproduction, Fertility and Development 10 471-478

Bogacki M, Jaroszewski JJ, Skarzynski DJ and Hansel W (2002) The influence of nitric oxide on cyclooxygenase and lipoxygenase products of arachodonic acid metabolism in the bovine corpus luteum in vivo. Biology of Reproduction $6 \mathbf{6}$ Supplement 1325 (Abstract)

Bogdan C (2001) Nitric oxide and the immune response Nature Immunology 2 907-916

Boiti C, Zerani M, Zampini D and Gobbetti A (2000) Nitric oxide synthase activity and progesterone release by isolated corpora lutea of rabbits in the early and mid-luteal phases of pseudopregnancy are modulated differentially by prostaglandin $E_{2}$ and prostaglandin $F_{2 \alpha}$ via adenyl cyclase and phospholipase C Journal of Endocrinology $\mathbf{1 6 4}$ 179-186

Burney S, Tamir S, Gal A and Tannenbaum SR (1997) A mechanistic analysis of nitric oxide-induced cellular toxicity Nitric Oxide 1 130-144

Dong YL, Gangula PRR and Yallampalli C (1996) Nitric oxide synthase isoforms in the rat uterus: differential regulation during pregnancy and labour Journal of Reproduction and Fertility 107 249-254

Dong YL, Gangula PRR, Fang L and Yallampalli C (1999) Nitric oxide reverses prostaglandin-induced inhibition in ovarian progesterone secretion in rats Human Reproduction 14 27-32

Drazen DL, Klein SL, Burnett AL, Wallach EE, Crone JK, Huang PL and Nelson RJ (1999) Reproductive function in female mice lacking the gene for endothelial nitric oxide synthase Nitric Oxide 3 366-374

Dunnam RC, Hill MJ, Lawson DM and Dunbar JC (1999) Ovarian hormone secretory response to gonadotropins and nitric oxide following chronic nitric oxide deficiency in the rat Biology of Reproduction 60 959-963

Eisenstein TK (2001) Implications of Salmonella-induced nitric oxide (NO) for host defense and vaccines: NO, an antimicrobial, antitumor immunosuppressive and immunoregulatory molecule Microbes and Infection 3 1223-1231

Friden BE, Runesson E, Hahlin M and Brannstrom M (2000) Evidence for nitric oxide acting as a luteolytic factor in the human corpus luteum Molecular Human Reproduction 6 397-403

Gobbetti A, Boiti C, Canali C and Zerani M (1999) Nitric oxide synthase acutely regulates progesterone production by in vitro cultured rabbit corpora lutea Journal of Endocrinology 160 275-283

Green LC, Wagner DA, Glogowski J, Skipper PL, Wishnok JS and Tannenbaum SR (1982) Analysis of nitrate, nitrite and ${ }^{15} \mathrm{~N}$ nitrate in biological fluids Analytical Biochemistry 126 131-138

Hinckley ST and Milvae RA (2001) Endothelin-1 mediates prostaglandin $\mathrm{F}_{2 \alpha}$-induced luteal regression in the ewe Biology of Reproduction $\mathbf{6 4}$ $1619-1623$

Ignarro LJ (1990) Biosynthesis and metabolism of endothelium-derived nitric oxide Annual Review of Pharmacology and Toxicology 30 535560

Jablonka-Shariff A and Olson LM (1998) The role of nitric oxide in oocyte meiotic maturation and ovulation: meiotic abnormalities of endothelial nitric oxide synthase knock-out mouse oocytes Endocrinology 139 2944-2954

Jaroszewski JJ and Hansel W (2000) Intraluteal administration of a nitric oxide synthase blocker stimulates progesterone and oxytocin secretion and prolongs the life span of the bovine corpus luteum Proceedings of the Society for Experimental Biology and Medicine 224 50-55

Jaroszewski JJ, Skarzynski DJ and Okuda K (2001) Nitric oxide as a local regulator in the mammalian ovary. In Reproductive Biotechnology: Reproductive Biotechnology Update and Its Related Physiology pp 105112 Eds H Miyamoto and N Manabe. Elsevier, Tokyo

Kiss JP (2000) Role of nitric oxide in the regulation of monoaminergic neurotransmission Brain Research Bulletin 52 459-466 
Levy N, Kobayashi S, Roth Z, Wolfenson D, Miyamoto A and Meidan R (2000) Administration of prostaglandin $F_{2 \alpha}$ during the early bovine luteal phase does not alter the expression of ET-1 and of its type A receptor: a possible cause for corpus luteum refractoriness Biology of Reproduction 63 377-382

Miyamoto Y, Skarzynski DJ and Okuda K (2000) Is tumor necrosis factor- $\alpha$ a trigger for the initiation of endometrial prostaglandin $F_{2 \alpha}$ release at luteolysis in cattle? Biology of Reproduction 62 1109-1115

Moncada S, Palmer RMJ and Higgs EA (1991) Nitric oxide: physiology, pathophysiology, and pharmacology Pharmacological Reviews 43 109142

Motta AB and Gimeno MAF (1997) Nitric oxide participates in the corpus luteum regression in ovaries isolated from pseudopregnant rats Canadian Journal of Physiology and Pharmacology 75 1335-1339

Motta AB, Estevez A, Tognetti T, Gimeno MAF and Franchi AM (2001) Dual effects of nitric oxide in functional and regressing rat corpus luteum Molecular Human Reproduction 7 43-47

Okuda K, Uenoyama Y, Fujita Y, Iga K, Sakamoto K and Kimura T (1997) Functional oxytocin receptors in bovine granulosa cells Biology of Reproduction 56 625-631

Olson LM, Jones-Burton CM and Jablonka-Shariff A (1996) Nitric oxide decreases estradiol synthesis of rat luteinized ovarian cells: possible role for nitric oxide in functional luteal regression Endocrinology 1373531 3539

Pate JL and Landis Keyes P (2001) Immune cells in the corpus luteum: friends or foes Reproduction 122 665-676

Petroff MG, Petroff BK and Pate JL (2001) Mechanisms of cytokine-induced death of cultured bovine luteal cells Reproduction 121 753-760

Rosselli M, Keller PJ and Dubey RK (1998) Role of nitric oxide in the biology, physiology and pathophysiology of reproduction Human Reproduction Update 4 3-24

Sessa WC (1994) The nitric oxide synthase family of proteins Journal of Vascular Research 31 131-143
Skarzynski DJ and Okuda K (1999) Sensitivity of bovine corpora lutea to prostaglandin $F_{2 \alpha}$ is dependent on progesterone, oxytocin and prostaglandins Biology of Reproduction 60 1292-1298

Skarzynski DJ and Okuda K (2000) Different actions of noradrenaline and nitric oxide on the output of prostaglandins and progesterone in cultured bovine luteal cells Prostaglandins and Other Lipid Mediators 60 $35-47$

Skarzynski DJ, Kobayashi S and Okuda K (2000) Influence of nitric oxide and noradrenaline on prostaglandin $\mathrm{PGF}_{2 \alpha}$-induced oxytocin secretion and intracellular calcium mobilization in cultured bovine luteal cells Biology of Reproduction 63 1000-1005

Skarzynski DJ, Jaroszewski JJ, Bah MM, Deptula KM, Barszczewska B and Gawronska B (2001) An inhibitor of nitric oxide synthase (L-NAME) blocks prostaglandin $\mathrm{PGF}_{2 \alpha}$-induced luteolysis in cattle Biotechnology, Agronomy Society and Environment 548 (P28) (Abstract)

Taniguchi H, Yokomizo Y and Okuda K (2002) Fas-Fas ligand system mediates luteal cell death in bovine corpus luteum Biology of Reproduction 66 754-759

Van Voorhis BJ, Dunn MS, Snyder GD and Weiner CP (1994) Nitric oxide: an autocrine regulator of human granulosa-luteal cell steroidogenesis Endocrinology 135 1799-1806

Wink DA, Osawa Y, Darbyshire JF, Jones CR, Eshenaur SC and Nims RW (1993) Inhibition of cytochromes progesterone 50 by nitric oxide and a nitric oxide-releasing agent Archives of Biochemistry and Biophysics $300115-123$

Received 8 August 2002.

First decision 11 October 2002.

Revised manuscript received 4 November 2002.

Accepted 26 November 2002. 